\title{
Is that different from the?
}

\author{
Soh Theng Quek, Bee Eng Wong \\ University Putra Malaysia, Malaysia
}

Received: July 27, 2019

Accepted: May 27, 2020

Published: August 1, 2020

doi:10.5296/jse.v10i3.15158

URL: https://doi.org/10.5296/jse.v10i3.15158

\begin{abstract}
English is a language with overt morphological representations of articles. On the other hand, Malay and Mandarin Chinese have none. In Malaysia, pupils are exposed to English articles as early as four years old. Despite early exposure, articles, or the definite article the specifically, appear to be a marked grammatical property for Chinese-speaking and Malay-speaking learners, two languages without articles. Based on the Fluctuation Hypothesis and Article Choice Parameter, this study seeks to investigate and compare the role of first language (L1) transfer on the article acquisition of the 77 L1 Chinese and 116 L1 Malay ESL learners, who were teacher trainees recruited from three teachers' training institutes in Malaysia. The respondents were tested utilising a production task and a comprehension task. The statistical analyses of the participants' performance revealed that only the advanced and intermediate groups of both L1 Chinese and L1 Malay ESL learners registered clear distinctions between the usage in the 'Unique and salient' and 'Unique and non-salient' categories and that usage in the 'Non-unique' category. The high accuracy rates suggest that L1 lexical transfer contributed to the positive performance by the ESL learners. The advanced and intermediate L1 Chinese and L1 Malay learners continuously interpreted the singular definite descriptions as referring to uniquely immediate salient entities similar to the demonstrative descriptions, making interpretations of the and that seemed similar.
\end{abstract}

Keywords: definiteness, demonstratives, grammaticalization, salient, transfer 


\section{Introduction}

The English articles which include the indefinite article $a(n)$, the definite article the, and the $z e r o(\varnothing)$ article are recognised as three functional words with one of the most challenging structural fundamentals (Chrabaszcz \& Jiang, 2014; Ekiert, 2004; García Mayo, 2008; Ionin \& Montrul, 2010; Liu \& Gleason, 2002; Master, 1987) for learners of English as a second language (ESL) to master. In Malaysia, English is used widely and students are exposed to English articles as early as four years old in kindergartens. Despite early exposure, first language (L1) Malay and first language (L1) Chinese adult learners make errors in the acquisition of the articles (Wong \& Chan, 2008; Wong \& Quek, 2007). The definite article the specifically is one of the marked grammatical properties for L1 Malay-speaking learners (Khazriyati Salehuddin, Tan, Marlyna Maros, \& Maros, 2006; Nor Hashimah Jalaluddin, Norsimah Mat Awal, \& Kesumawati Abu Bakar, 2008; Wong \& Quek, 2007).

Based on previous studies on second language (L2) article acquisition, article omission and article substitution are two common types of errors committed by L2 learners. Analyses of such errors show the level of L2 learners' awareness of articles and the representations of articles in their interlanguage grammar (Trenkic, 2008, p.1). L2 grammar is proposed to be constrained by Universal Grammar (UG) and L2 learners are able to acquire features not instantiated in their L1 through UG access (Hawkins, 2004; Hawkins et al., 2006; Ionin \& Montrul, 2010; Snape, Leung, et al., 2006; Trenkic, 2008; Xu et al., 2016). Demonstratives are claimed to be the common source of articles, as can be seen in the English definite article, the which has developed from that (Lyons, 1999; p. 331). In many contexts including the anaphoric contexts, the and that are interchangeable and still maintain the semantic meaning.

The purpose of this study is to explore the relationship between L1 and L2 learners' article acquisition and determine if L1 affects the use of English articles among the L1 Malay and L1 Chinese-speaking ESL learners with article-less L1 backgrounds. This study will address the following research question:

How do L1 Malay and L1 Chinese ESL learners compute and distinguish definite and demonstrative accounts in the use of the and that respectively in singular contexts?

\section{Literature Review}

Over the decades, researchers have found that the semantic context ( \pm definite vs \pm specificity) of a noun (Chondrogianni, Vasić, Marinis, \& Blom, 2015; Fodor \& Sag, 1982; Geng, 2010) also affects L2 learners' article accuracy rate which is triggered by their ability to determine not only the countability (countable versus abstract, and singular versus plural) (Lee Amuzie \& Spinner, 2013; Lee, 2012; Miller, 2005; White, 2009; Whong, Gil, \& Marsden, 2013) and also the familiarity or uniqueness of a noun (Abbott, 2006, 2014; Hinenoya, 2008; Lee, 2007; Snape, 2006). A number of studies propose the positive influence of L1 transfer on L2 English article acquisition (Chrabaszcz \& Jiang, 2014; Crosthwaite, 2014; Ionin, Baek, Kim, Ko, \& Wexler, 2011, 2012; Ionin, Zubizarreta, \& Maldonado, 2008; P. Master, 1997; Robertson, 2000; Snape, García Mayo, \& Gürel, 2013; Zdorenko \& Paradis, 2008).

There is a close relationship between definite and demonstrative determiners. In many 
contexts, the and that could be used interchangeably and claimed to share the same central semantics of uniqueness. Hence, it is proposed that the second language (L2) learners of English transfer the semantics of that lexically from their first language (L1) to interpret the definite article the (Ionin et al., 2012; Ionin \& Montrul, 2010b; Lee, 2012; Roberts, 2002; Wolter, 2006).

\subsection{Fluctuation Hypothesis and the effects of L1 transfer in L2 article acquisition}

Article Choice Parameter (ACP) and Fluctuation Hypothesis (FH) were first proposed by Ionin et al. (2004). Many studies have since tested them with different L2 populations with [-Art] languages (Ionin et al., 2004b; Kim \& Lakshmanan, 2008; Kim \& Lakshmanan, 2009; Ko et al., 2006, 2009; among many others) and these are followed suit by L2 with [+Art] languages (Al-Mohanna, 2014; Cho, 2016; Kupisch, 2012; Montrul \& Ionin, 2010; Montrul, 2011; Morales-Reyes \& Soler, 2016; Snape et al., 2006; Snape, 2006, 2008; White, 2008; Zdorenko \& Paradis, 2008). These studies found similar and contradicting results but some interesting variations are also uncovered. Studies that tested effects of L1 transfer on L2 adult learners with Fluctuation Hypothesis and Article Choice Parameter can be divided into two main groups; first languages with articles [+Art] and those without articles [-Art].

L2 learners whose first languages with articles [+Art] (such as French and Spanish) and overt semantic features of articles have the tendency to transfer the features that encode definiteness from their L1s and thus assist them in their article acquisition process. On the contrary, L2 learners with first languages without articles [-Art] such as Chinese, Russian, Korean and Japanese registered distinctive traces of fluctuation and L1 transfer effect (see Thomas, 1989; Ionin, Ko, \& Wexler, 2004; Garcia-Mayo \& Hawkins, 2009 Snape et al., 2013; Ionin et al., 2011). Although article-less, these languages have demonstratives to denote definiteness. Demonstratives are claimed to share the same central semantics of uniqueness as definites (Wolter, 2006).

\subsection{L1 Transfer and languages with definiteness-based articles}

Since the proposal of ACP and FH, many studies have tested them with different L2 populations. In order to tackle an open question pertaining to the role of UG, fluctuation and L1 transfer in the second language acquisition of articles, a number of studies have focused on comparing acquisition patterns of L2 learners with [+Art] and [-Art] first languages with English as the base. Ionin, Zubizarreta and Maldonado (2008) administered an experimental study on twenty-three L1 Russian and twenty-four L1 Spanish L2 learners of English, with six adult English native speakers as controls. Fluctuation patterns were traced among the L1 Russian learners but not with the L1 Spanish learners instead they were comparatively highly accurate (target-like) in the elicitation task. The positive transfer of definiteness from L1 facilitates the L1 Spanish learners in the article acquisition whereas the L1 Russian learners fluctuate due to L1 interference or dissimilarities between L1 and L2 (Bardovi-harlig \& Sprouse, 2018, p.1).

The fluctuation patterns exhibited by the Japanese in Hawkins et al.'s (2006) study was in fact similar to the Russian and Korean speakers (in Ionin et al., 2004) and thus reaffirms Ionin 
et al.'s claim that speakers of [-Art] languages follow a developmental stage permitting a choice offered neither by the L1 nor the L2 (L2 interlanguage grammar). Based on FH, that input will eventually lead learners 'to set the parameter to the appropriate value' (2004a: 16). In contrast, the L1 Greek speakers and native speakers mainly chose the or $a$ to mark definiteness or indefiniteness. In line with $\mathrm{FH}$, the L1 Greek's performance proves that fluctuation is not a general L2 developmental phenomenon for L2 speakers with an L1 that uses articles to mark definiteness like English. Hawkins et al. (2006) asserts that the L1 Japanese speakers access $[ \pm$ definite $]$ and $[ \pm$ specific $]$ directly from UG directory and not from the features grammaticalized in their L1.

Adopting the Wolter's (2006) semantic proposal, Ionin, Baek, Kim, Ko, and Wexler (2011) claim that L2 learners from article-less L1's adopt demonstrative analysis to both the and that. In their quest to determine whether L2 learners with [-Art] L1 can distinguish definites from demonstratives, Ionin et al. (2011) conducted an empirical study on 33 L1 Korean L2 learners of English. L1 Koreans' performance in the definite contexts indicated that learners used the to denote uniqueness/ maximality. As for the comprehension task, the findings showed that the native speakers made a clear distinction between the definites and demonstratives in line with Wolter's (2006) analysis by denoting plural definites as the maximal set in the discourse context (i.e., all four pencils, or knives, or pens in the picture), and plural demonstratives as the maximal set in the immediate situation made salient by the previous action (i.e., the two apples, or bananas, or balloons just acted upon). Conversely, the L1 Koreans acted upon just the two objects previously acted upon to display preference for the maximal set in the immediately salient situation in both cases, treating definites and demonstratives as equivalents. Ionin et al. (2011) asserted that L1 has influenced the L2-learners' demonstrative analysis because Korean has only demonstratives.

\section{Linguistic Assumptions}

Ever since extensive research are being done on the acquisition of articles, second language (L2) learners of English with first languages (L1) without articles (-Art) such as Mandarin Chinese, Japanese, Korean, and Russian (Ionin, Ko, \& Wexler, 2003; Thomas, 1989) seem to find the acquisition of the English article system even more difficult than those learners whose L1 has an article system (Kim \& Lakshmanan, 2009; Montrul \& Ionin, 2010). To better understand the integral underlying processes in acquiring the English article system, this paper provides a sketch of the grammatical and semantic properties of the noun phrase (NP) in Mandarin Chinese, Malay language and English, specifically with regard to the notions of definiteness $([ \pm \mathrm{Def}]$ and followed by the demonstrative descriptions of these three languages.

\subsection{Definite and Demonstrative Descriptions in Mandarin Chinese}

In Mandarin Chinese, definite or indefinite noun phrases must be referential in order to be definites or indefinites ( $\mathrm{Li}$ and Thompson, 1981, p. 129). The speaker must have a particular referent in mind and intends to refer to it in order to classify the context as referential (Lyons 1999, p.178). A referential noun phrase refers to an entity which may be singular or plural, physical or conceptual, real or hypothetical. Some of the referential noun phrases are bold in 


\section{Macrothink}

the examples from (1) and (2) given below:

$\begin{array}{llclll}\text { zhèi- } & \text { tiào xiāngjiāo } & \text { wō } & \text { chī- } & \text { bu } & \text {-xià } \\ \text { this - } & \text { CL banana } & \text { I } & \text { eat- } & \text { can't } & \text {-descend }\end{array}$

This banana I can't eat.

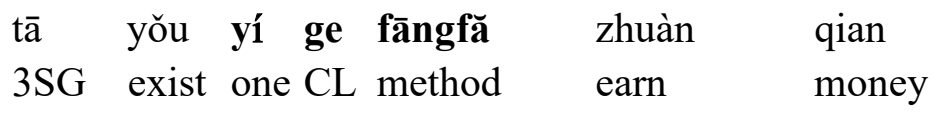

$\mathrm{He} / \mathrm{She}$ has an idea for making money.

From Li and Thompson (1981, p.127)

A referential noun phrase with a classifier phrase is always definite (refer $3 \& 4)$ :

(3)
zhèi - ge rén
this - CL person
this person

$$
\begin{aligned}
& \text { nèi - xiē yǐzi } \\
& \text { That- PL chair } \\
& \text { those chairs }
\end{aligned}
$$

(4)

\subsection{Definite and Demonstrative Descriptions in Malay}

The use of itu 'that' and ini 'this' in the following sentences demonstrates the notion of definiteness in the Malay noun phrases, although they are not equivalent to the English article the. In the first part of their book, Nik Safiah Karim, Farid M. Onn, Hashim Hj. Musa and Abdul Hamid Mahmood (2006, p. 102) state that ini and itu are two words used to refer to a thing or subject that is near or far respectively, as shown in examples (5) and (6).

(5) Ini hasil nukilan penulis muda itu.

DET outcome excerpt writer young DET

This is the young writer's excerpt.

(6) Itu buku biografi Pendeta Za'ba.

DET book biography Pendeta Za 'ba

That is Pendeta Za 'ba's biography book.

According to Nik Safiah Karim et al. (2006), determiners are elements that give the notion of definiteness to a noun phrase and they can be positioned before or after the noun. There are two types of determiners: Penentu Hadapan (Pre-Determiner) and Penentu Belakang (Post-Determiner). As shown in (7), the Pre-Determiner generally occurs in front of nouns, consists of numerals followed by classifiers. The use of seorang here is claimed to be functioning almost like the indefinite article $a$, although not as an equivalent.

$$
\begin{array}{ll}
\text { seorang askar } & \text { soldier } \\
\text { one CLS } & \text { a/one soldier }
\end{array}
$$

Post-Determiners, itu that and ini this, are elements that occur after the nouns, as shown in (8) and (9). The use of itu 'that' and ini 'this' in these sentences demonstrates a notion of definiteness in the Malay noun phrases, although they are not equivalent to the English article 
the.

(8)

$$
\begin{aligned}
& \text { orang itu } \\
& \text { person Det } \\
& \text { that person } \\
& \text { (9) rumah ini } \\
& \text { house Det }
\end{aligned}
$$

this house

\subsection{Definite and Demonstrative Descriptions in English}

Just like many languages, English definite and demonstratives determiners are claimed to have a close relationship. In many semantic contexts, the definite article the and demonstrative determiner that can be used interchangeably as well as the anophoric context shown in (10) (Lyons, 1999; K. L. Wolter, 2006) due to their sharing of the same central semantics of uniqueness. Both the and that can be used in the context in (10) as the conditions on uniqueness are met.

(10) A girl was sitting next to a window as I walked into the room. As I was leaving, the/that girl started to cry bitterly.

This study replicates Ionin et al's (2012) semantic proposal of demonstratives and definites which is a combination of Wolter's (2006) semantic proposal and the semantic of uniqueness where both denote uniqueness/maximality.

\section{Research Methodology}

The research is designed to investigate and compare the possibility of L1 transfer on article acquisition of the L1 Chinese and L1 Malay ESL learners across three proficiency levels. The performance of the L1 Chinese and L1 Malay ESL learners was measured by the article accuracy scores obtained from two production tests consisting of a written and a comprehension task. A group of native speakers was recruited to serve as the control group in the pilot study. For statistical analyses, the mean scores of the participants in each group (L1 Chinese and L1 Malay) were recorded and analysed using the same test measures such as ANOVA, pairwise t-test, Scheffé post hoc test and repeated measures ANOVA (Creswell, 2012, p. 325). Descriptive and inferential analyses were conducted using the SPSS version 23.

\subsection{Participants}

A total of 193 adult ESL learners involving 77 L1 Chinese speakers and 116 L1 Malay speakers from three teachers' training institutes in Terengganu, Kuala Lumpur and Seremban, Malaysia were recruited for the study. The learners' levels of proficiency were determined by the standardised Common European Framework of Reference for Languages (CEFR)(Council of Europe, 2001) using the Oxford Online Placement Test (OOPT). The OOPT was carried out last online after the forced-choice written elicited production task (refer to examples in Appendix 1) and picture-based comprehension task (Ionin et al., 2012) (refer to examples in Appendix 2) were completed by the participants on different occasions. 


\subsection{Instruments}

The picture-based comprehension and forced-choice elicited production tasks taken from Ionin, Baek, Kim, Ko, and Wexler (2012) were carried out to determine the ESL learners' interpretation of uniqueness. The focus of this part of the study was to determine whether L2 learners' transfer their perception of uniqueness from the demonstrative itu or nei 'that' to interpret the definite Noun Phrase (NP) in the targeted sentence.

The forced-choice elicited production task had 32 items, divided into eight categories of four items each. Each item consisted of a short story of four or five sentences. Participants read a series of mini stories and filled in the blank in one of the sentences (but not the last sentence) in each story with a choice of four determiners, the, that, a, or one. They were given two tasks to be fulfilled. Firstly, they were asked to choose any of the four answers given to fill in the blank which they deemed appropriate. Only three out of the eight test categories, shown in Appendix 2, where the marked singular NP was used anaphorically, were the focus of this study.

The picture-based comprehension task was a modification consisting of 40 items, divided into 10 conditions of four items each (refer to Appendix 1). In the comprehension task, the participants read the three level of instructions given, viewed pictures of objects and drew arithmetical shapes on the objects as directed.

\section{Findings and Discussion}

Studies have shown that positive L1 transfer assists L2 learners whose L1s are with articles (for example L1 Spanish and L1 Greek) in their acquisition of English articles. This study hypothesized that the ESL learners from article-less L1s such as Mandarin Chinese and Malay language might interpret English definites as having the meaning of demonstratives. Since Mandarin and Malay do not have articles, there is a high possibility that the learners transfer the semantic meanings of demonstratives from their L1s and associate them to definites in a process known as lexical transfer (Ionin et al., 2012, p. 71; Kim \& Lakshmanan, 2009, p. 95; Robertson, 2000, p. 169). The L1 Chinese and L1 Malay L2 learners are expected to equate nei or itu 'that' to that or the or both that and the. The predictions for L1 transfer are formulated due to the absence of articles in Mandarin Chinese and Malay as compared to the English language facts.

\subsection{Computation of 'the' $v$ s 'that'}

To compare the effect of the choices in the three categories on the ESL groups, the percentage of the choices out of all the + that choices for each of the three test categories was conducted. The three groups' performance on each category was checked if it was significantly different from chance using one-way ANOVA. It is predicted that if the respondents could not differentiate between the and that, they should choose each one about $50 \%$ of the time (Ionin, Baek, Kim, Ko, \& Wexler, 2012; p.82).

Figures 1, 2 and 3 report the percentages of the frequency each determiner form ( $a$, one, the or that) was selected as the 'best choice' for the blank in the short stories; the results are divided by category, and by proficiency level of the L1 Chinese and L1 Malay ESL learners. 


\section{Mll Macrothink}

Journal of Studies in Education

ISSN 2162-6952

2020, Vol. 10, No. 3

The advanced group of L1 Chinese ESL learners showed the greatest resemblance with the advanced group of L1 Malay learners for their choice of the in the 'Unique and non-salient' category $88.7 \%$ and $90.7 \%$ respectively (refer Figure 2). The advanced L1 Chinese clinched $82.3 \%$ of the choice in the 'Unique and salient' category (refer Figure 1) and $81.5 \%$ of that in the 'Non-unique' category (refer Figure 3). As for their Malay counterparts, the advanced L1 Malay ESL learners rated the at $76.4 \%$ of the time in the 'Unique and salient' category and a $75 \%$ acceptance rate for that in the 'Non-unique' category.

The intermediate L1 Chinese learners lagged closely behind the intermediate L1 Malay learners with slightly lower percentages $(62.1 \%$ and $75 \%)$ for the choices in both the 'Unique' categories and that in the 'Non-unique' category (79.6\%). At the same time, the was also the strongly preferred response by the intermediate Malay learners, with the chosen more than $70 \%$ of the time in two 'Unique' categories as compared to that which was preferred in the 'Non-unique' category at $59.7 \%$.

On the contrary, the elementary Chinese learners registered $65.6 \%$, which is $3.5 \%$ higher than the intermediate group in the 'Unique and salient' category but registered the lowest percentages in the choices $(65.6 \%)$ for the 'Unique and non-salient' category and that $(64.6 \%)$ for the 'Non-unique' category. Meanwhile the elementary Malay learners rated the as acceptable at $50.9 \%$ and $47.2 \%$ of the time in the 'Unique' categories and chose that $45.4 \%$ of the time which is $2.8 \%$ more than the $(42.6 \%)$ in the 'Non-unique' category.

The highest percentages of the choice were found in the 'Unique and non-salient' category. The percentages of the choice increased parallel to the proficiency level of the L1 Chinese and L1 Malay ESL learners for the two 'Unique' categories. Conversely, the lowest percentages of the choice are found in the 'Non-unique' category among the advanced L1 Chinese and Malay ESL learners, and also the intermediate L1 Chinese learners. The advanced learners from both L1 groups also chose the more than $90 \%$ of the time in both the 'Unique' categories. Even the elementary groups of L1 Chinese and L1 Malay ESL learners registered higher percentages in the use of the in both 'Unique' categories as compared to that usage in the 'Non-unique' category. The elementary Malay learners used the and that interchangeably about $50 \%$ of the time in this category. Based on $\mathrm{FH}$, the elementary groups showed traces of fluctuating until sufficient input lead to the correct parameters which enable them to differentiate the use of the and that.

In the production task, the advanced and intermediate learners from both ESL groups were fairly target-like in their performance, preferring the for the 'Unique and salient' and 'Unique and non-salient' categories as well as that for the 'Non-unique' category. The advanced L1 Malay and L1 Chinese groups seemed to perform near native-like in the Non-unique category, choosing that more than the whereby in this category that should be preferred over the. 


\section{Unique and salient category}

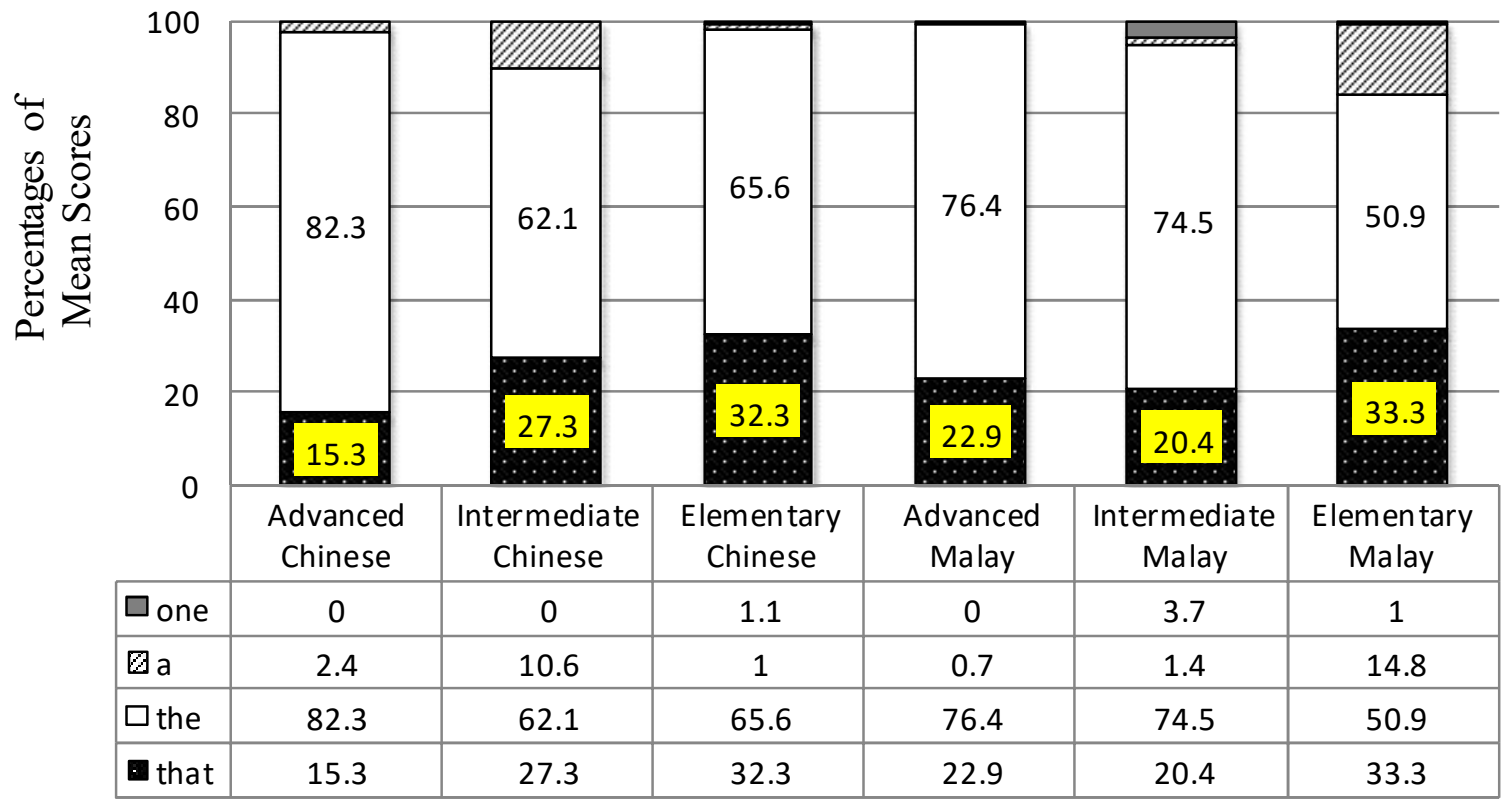

English Proficiency

Figure 1. Proportion of L1 Chinese and L1 Malay ESL learners' best choice of determiner form (that, the, a, one) in the 'Unique and salient' category

Unique and non-salient category

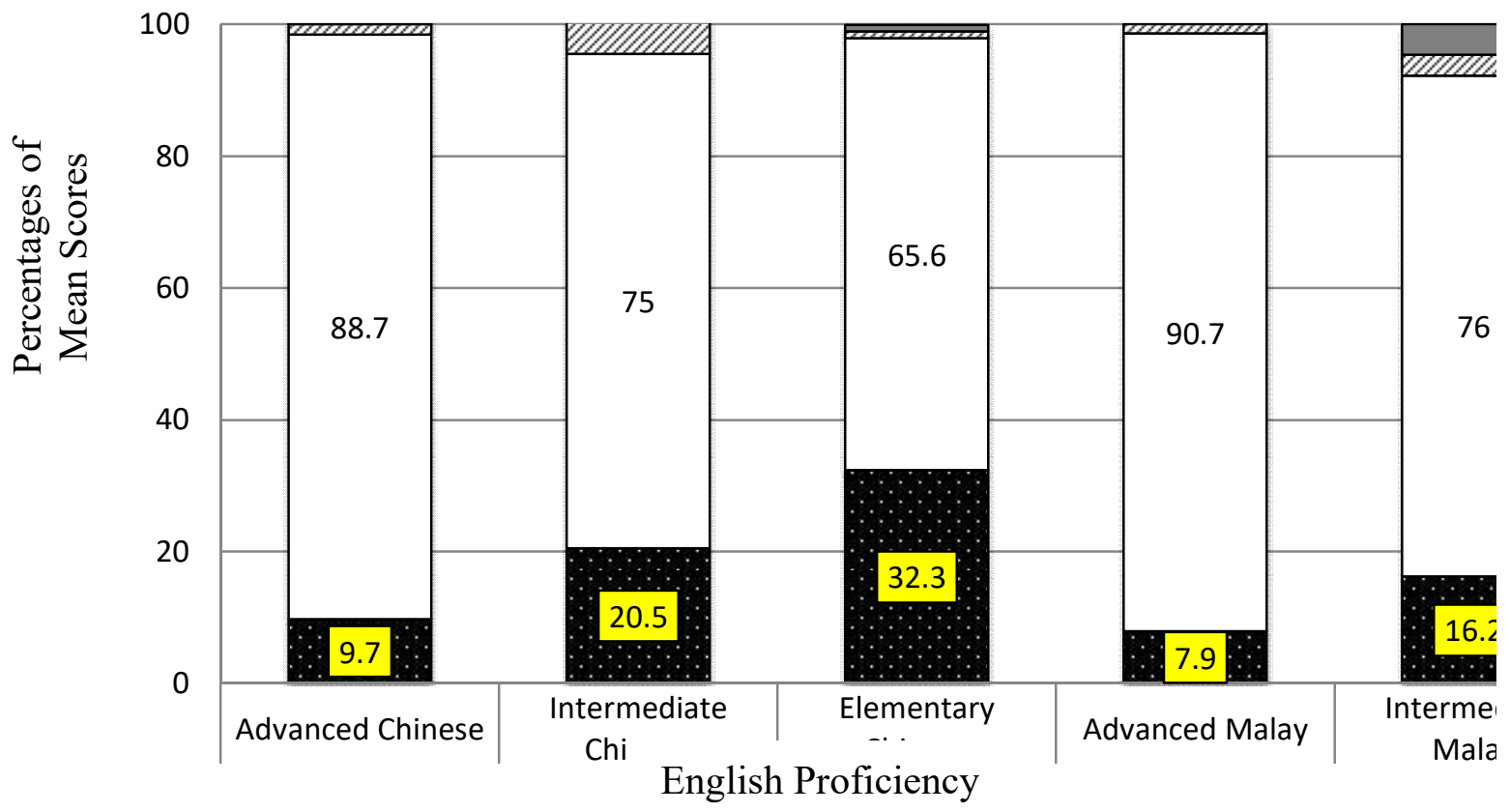

Figure 2. Proportion of L1 Chinese and L1 Malay ESL learners' best choice of determiner form (that, the, a, one) in 'Unique and non-salient' category 


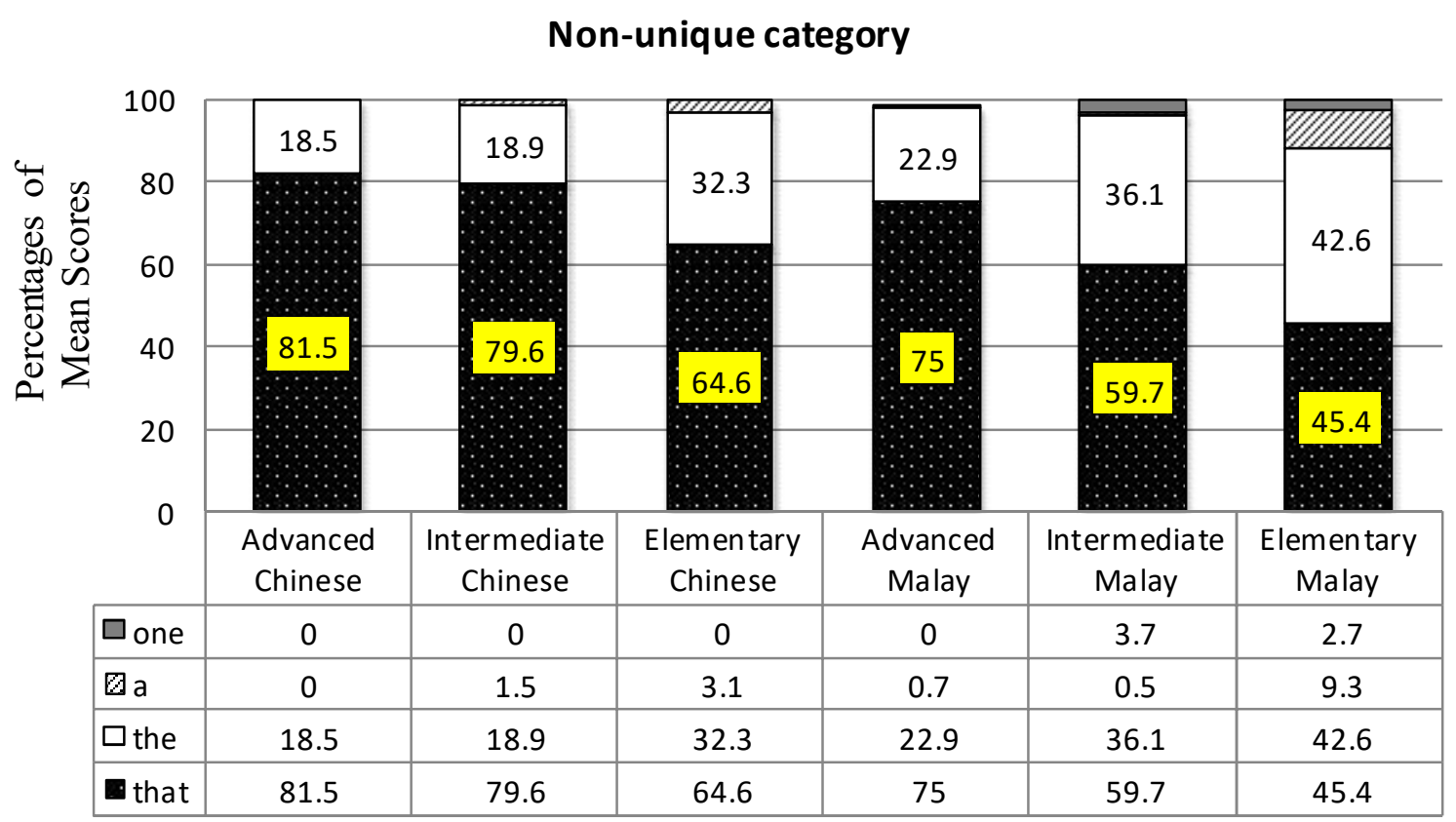

English Proficiency

Figure 3. Proportion of L1 Chinese and L1 Malay ESL learners' best choice of deteminer form (that, the, a, one) for 'Non-unique' category

By comparing the ratio of the out of all the + that choices, only the elementary L1 Malay learners performed significantly different from the advanced group in the 'Unique and salient' category. For the 'Unique and non-salient' category, significant differences were registered by both elementary groups of L1 Chinese and L1 Malay ESL learners with the native speakers. In fact, the elementary groups from both L1s showed preference for the over that in the 'Unique non-salient' category although native speakers exhibited more resilient article choice. The elementary groups had not fully acquired the fact that the requires uniqueness in the discourse. However, all the ESL learners' performance did not differ significantly in the 'Non-unique' category to show ESL learners' distinct mastery on the use of demonstrative that.

This shows that 'Non-unique' category is not a marked context for the ESL learners as they could use that more accurately in this category as compared to the uses in the two 'Unique' categories. When uniqueness was established in the discourse, L1 Chinese and L1 Malay learners did not use the and that as entirely compatible as they displayed an inclination to choose the over that, similar to the native speakers. However, in the 'Non-unique' category, the elementary Malay ESL group used the and that interchangeably and hence failed to distinguish the from that. Based on the data in Tables 1 and 2, the predictions were largely supported by the L1 Chinese and L1 Malay learners. The two groups of ESL learners show very similar patterns in their use of the in the two 'Unique' categories and that 'Non-unique' category concerned despite the quantitative differences. Crucially, the L1 Chinese and L1 Malay ESL learners probably map nei and itu respectively onto both the and that. 


\subsection{Interpretation of Uniqueness and L1 transfer in Singular Conditions}

Based on Wolter's (2003, p. 12) proposal of definites and demonstratives, it is compulsory for definite and demonstrative singular NPs to denote uniquely for the native speakers. For definites, uniqueness is computed relatively to the default situation. In this scenario, saliency is taken into account to decide the usage of articles or demonstratives. For L2 learners, there are possibly two ways of forming the discourse situation: the participant may take the entire situation to be the discourse situation or the participant may take just the immediate situation established in response to the first line. Turning to demonstratives, the relevant situation is the non-default situation, immediately salient situation.

The results of the three singular conditions of the L1 Chinese and L1 Malay ESL learners are shown in Tables 1 and 2 respectively. The advanced groups of L1 Chinese and L1 Malay ESL learners chose mainly 'same' responses in the definite $(88.3 \%$ and $88.9 \%$ respectively) and demonstrative (97.5\% and $99.3 \%$ respectively) singular conditions. The advanced L2 learners seem to have established the default discourse situation in response to line 1 for both the definite and demonstrative conditions to compute uniqueness. Their preferences to act upon the 'same' responses for these two categories ( $88.3 \%$ and $97.5 \%$ respectively) were almost as strong as the native speakers. For the definite singular condition (refer to Table 1), the intermediate L1 Chinese learners showed essentially similar trait performances as the intermediate L1 Malay-speaking learners. The advanced Chinese learners showed the highest preference for the 'same' response at $88.3 \%$ while the elementary learners scored approximately $50 \%$ of 'same' $(54.2 \%)$ and 'different' $(45.8 \%)$ responses. However, the elementary learners chose $92.7 \%$ of 'same' responses in the demonstrative singular condition as compared to $86.2 \%$ scored by the intermediate learners.

Based on the results, the learners registered the 'same' object in line 2 as response to line 1 most of the time and did not seem to act upon any object randomly or by chance in the demonstrative singular condition. This shows that the learners are distinctly able to differentiate between the definite and demonstrative conditions, and are not adopting a presuppositional analysis of 'the' in the singular conditions.

Table 1. Mean percentages of L1 Chinese ESL Learners' responses to line 2 in singular conditions

\begin{tabular}{lccccccccc}
\hline Condition & \multicolumn{3}{c}{$\begin{array}{c}\text { definite singular } \\
\text { 'the, }\end{array}$} & \multicolumn{4}{c}{$\begin{array}{c}\text { demonstrative } \\
\text { singular 'that' }\end{array}$} & \multicolumn{3}{c}{$\begin{array}{c}\text { indefinite singular } \\
\text { ' } a \text { ' }\end{array}$} \\
\hline & Ele & Int & $\mathrm{Adv}$ & Ele & Int & $\mathrm{Adv}$ & Ele & Int & $\mathrm{Adv}$ \\
\hline \% ALL response & 0 & 0 & 0 & 1 & 0 & .8 & 0 & 0 & 0 \\
\hline \%SAME response & 54.2 & 73.3 & 88.3 & $\mathbf{9 2 . 7}$ & $\mathbf{8 6 . 2}$ & $\mathbf{9 7 . 5}$ & 1 & 4.3 & 1.7 \\
\hline $\begin{array}{l}\text { \% DIFFERENT } \\
\text { response }\end{array}$ & 45.8 & 26.7 & 11.7 & 6.3 & 13.8 & 1.7 & $\mathbf{9 9}$ & $\mathbf{9 5 . 7}$ & $\mathbf{9 8 . 3}$ \\
\hline
\end{tabular}


Table 2. Mean percentages of L1 Malay ESL Learners' responses to line 2 in singular conditions

\begin{tabular}{lcccccccccc}
\hline Condition & \multicolumn{3}{c}{$\begin{array}{c}\text { definite singular } \\
\text { 'the' }\end{array}$} & \multicolumn{4}{c}{$\begin{array}{c}\text { demonstrative } \\
\text { singular 'that' }\end{array}$} & \multicolumn{4}{c}{$\begin{array}{c}\text { indefinite singular } \\
\text { ' } a\end{array}$} \\
\hline & Ele & Int & $\mathrm{Adv}$ & Ele & Int & $\mathrm{Adv}$ & Ele & Int & $\mathrm{Adv}$ \\
\hline \% ALL response & 2.8 & .5 & 0 & 1.9 & 0 & 0 & .9 & 0 & .7 \\
\hline \%SAME response & 41.7 & 74.1 & 88.9 & $\mathbf{6 8 . 5}$ & 93.1 & $\mathbf{9 9 . 3}$ & 20.4 & 5.1 & 7.6 \\
\hline $\begin{array}{l}\text { \%DIFFERENT } \\
\text { response }\end{array}$ & 55.6 & 25.5 & 11.1 & 29.6 & 6.9 & .7 & 78.7 & 94.9 & 91.7 \\
\hline
\end{tabular}

The results for the three singular conditions of the L1 Malay ESL learners are given in Table 2. Similar patterns of responses are distinctly visible between the two groups of ESL learners. The results for the indefinite singular condition show higher percentages in the 'different' response as compared to the 'same' response for the second line in response to the first line for the three groups of proficiency of both sets of ESL learners indicating that the learners do pay attention to the form of determiner used and answers are not chosen randomly.

The L1 intermediate and advanced Malay learners' performance in the definite and demonstrative singular categories resembled the L1 Chinese learners'. The advanced and intermediate Malay learners always registered the 'same' responses in the definite and demonstrative singular conditions similar to their Chinese counterparts which are acceptable and correct based on the native speakers' responses. As for the elementary Chinese learners, they showed an almost equal preference for 'same' and 'different' responses when uniqueness was recognized in the definite discourse. On the other hand, in the demonstrative condition, the elementary Chinese group exhibited a quite high preference (92.7\%) for 'same' responses only, even higher than the intermediate Chinese group.

\section{Conclusion}

Figures 1, 2 and 3 show similar preferences across groups in the production task: the two 'Unique' categories registered highest frequency use of the while that was most favoured for the 'Non-unique' category among the six groups of ESL learners. Results of the advanced L1 Chinese and L1 Malay ESL learners were quite similar and target-like on all the three categories. The results show that the advanced and intermediate Malay learners were target-like in their performance and they exhibited differentiation between the definite and demonstrative singular conditions especially the advanced group. Both the elementary Chinese learners and the elementary Malay learners portrayed fluctuation patterns in the interpretation of the in the definite condition. All the five groups of ESL learners were able to differentiate between the uses of the and that. Based on the results, the elementary L1 Malay ESL learners used the and that interchangeably in the 'Non-unique' category. Hence, they seemed to treat definite and demonstrative descriptions similarly. Coming back to the predictions, the results showed that majority of the Malay learners treated the and that differently as definites and demonstratives. In addition, the higher accuracy rates recorded in the 'Non-unique' category for both advanced Chinese and Malay groups show that there is a possibility of L1 transfer lexically that assists the ESL learners in their interpretations of the 
and that.

In the comprehension task, both advanced groups of L1 Chinese and L1 Malay ESL learners treated the definite and demonstrative singular as denoting uniquely. However, they did not act upon 'all' in the three singular conditions (the highest percentage for the 'all' response was $2.8 \%$ by the elementary L1 Malay group). This reflects the learners' ability to distinguish uniqueness based on the discourse given.

The advanced L1 Chinese and L1 Malay speakers seemed to interpret the definite and demonstrative singular NPs similarly as unique, just-mentioned, salient referents in the discourse. On the contrary, the elementary learners viewed definite and demonstrative as immediately salient entities consistent with the proposal by Ionin, Baek, Kim, Ko and Wexler (2012). Likewise, the advanced learners seemed to treat the in the definite condition and that in the demonstrative condition quite similarly as the referent is treated as unique in the immediate salient situation based on their highest rates of 'same' responses in both singular conditions which were even higher than the native speakers. On the other hand, the elementary Chinese group did not interpret the and that as completely interchangeable in the definite singular condition. The results of the elementary Chinese learners are more compatible with the possibility that that is mapped on to nei as a demonstrative. However, they have not yet acquired the fact that the here requires uniqueness with regard to the situation established in response to line 1 in the definite singular discourse. Although the intermediate Chinese learners acted upon the 'same' responses at a lower rate $(86.2 \%)$ compared to the advanced and elementary groups, their performance is considered as accurate as the accuracy rate is above $75 \%$. There might be some conflict and confusion among the intermediate Chinese learners in interpreting that as nei, indicating signs of fluctuation. The high percentages of 'same' responses registered by the intermediate and advanced Chinese and Malay learners in the definite and demonstrative conditions indicate a possibility that nei or itu 'that' are mapped on to the and that by the L1 Malay and L1 Chinese ESL learners. Judging by the high percentages of 'different' responses in the indefinite contexts for all the Chinese learners of three proficiency levels, it seems that the numeral $y i$ 'one' in Mandarin Chinese is fully grammaticalized into the indefinite article, $a$ whereas the numeral satu, se 'one' in Malay is partially grammaticalized into the indefinite article $a$.

In conclusion, it is found that the results in the singular conditions do not tease apart the definite analysis the from the demonstrative analysis that because both analyses predict actions on the 'same' object. It is recommended that L2 learners' performance on the plural conditions has to be included to further determine the L2 learners' interpretation of the and those.

\section{References}

Abbott, B. (2006). Definite and Indefinite. In Encyclopedia of Language and Linguistics, 2nd edition (pp. 392-399). https://doi.org/10.1016/B0-08-044854-2/01089-0 


\section{$\triangle$ Macrothink}

Journal of Studies in Education

ISSN 2162-6952

2020, Vol. 10, No. 3

Abbott, B. (2014). The indefiniteness of definiteness. In T. Gamerschlag, D. Gerland, R. Osswald, \& W. Petersen (Eds.), Frames and Concept Types: Applications in Language and Philosophy (pp. 323-341). Springer International Publishing. https://doi.org/10.1007/978-3-319-01541-5_14

Al-Mohanna, A. D. M. (2014). Errors in the Usage of the English Definite/Indefinite articles among Saudi University-level students. International Journal of Arts \& Sciences, 07(03), 79-95.

Bardovi-harlig, K., \& Sprouse, R. A. (2018). Negative Versus Positive Transfer. The TESOL Encyclopedia of English Language Teaching, 1-6.

https://doi.org/10.1002/9781118784235.eelt0084

Cho, J. (2016). The acquisition of different types of definite noun phrases in L2-English. International Journal of Bilingualism, 1-16. https://doi.org/10.1177/1367006916629577

Chondrogianni, V., Vasić, N., Marinis, T., \& Blom, E. (2015). Production and on-line comprehension of definiteness in English and Dutch by monolingual and sequential bilingual children. Second Language Research, 1-33. https://doi.org/10.1177/0267658314564461

Chrabaszcz, A., \& Jiang, N. (2014). The role of the native language in the use of the English nongeneric definite article by L2 learners: A cross-linguistic comparison. Second Language Research, 30(3), 351-379. https://doi.org/10.1177/0267658313493432

Council of Europe. (2001). Common European framework of reference for languages: Learning, teaching, assessment. Cambridge, UK: Cambridge University Press.

Creswell, J. W. (2012). Educational research: Planning, conducting, and evaluating quantitative and qualitative research. Educational Research (Vol. 4). https://doi.org/10.1017/CBO9781107415324.004

Crosthwaite, P. R. (2014). Definite Discourse-New Reference in L1 and L2: A Study of Bridging in Mandarin, Korean, and English. Language Learning, 64(3), 456-492. https://doi.org/10.1111/lang.12062

Ekiert, M. (2004). Acquisition of the English article system by speakers of Polish in ESL and EFL settings. Teacher's College, Columbia University Working Papers in TESOL \& Applied Linguistics, 4(1), 1-23. https://doi.org/10.7916/D81C28DK

Fodor, J. D., \& Sag, I. A. (1982). Referential and quantificational indefinites. Linguistics and Philosophy, 5(3), 355-398. https://doi.org/10.1007/BF00351459

García Mayo, M. del P. (2008). The acquisition of four nongeneric uses of the article the by Spanish EFL learners. System, 36(4), 550-565. https://doi.org/10.1016/j.system.2008.08.001

Geng, J. (2010). The Semantic Analysis of the Definite Article Misuse by Chinese Learners of English. Asian Social Science, 6(7), 180-185. https://doi.org/10.5539/ass.v6n7p180

Hawkins, R. (2004). The contribution of the theory of Universal Grammar to our understanding of the acquisition of French as a second language. Journal of French 
Language Studies, 14(3), 233-255. https://doi.org/10.1017/S0959269504001784

Hawkins, R., Al-Eid, S., Almahboob, I., Athanasopoulos, P., Chaengchenkit, R., Hu, J., Mohammad Rezai, Jaensch, C., Jeon, Y., Jiang, A., Leung, Y.I., Matsunaga, K., Ortega, M., Sarko, G., Snape, N., \& Velasco-Zarate, K. (2006). Accounting for English article interpretation by L2 speakers. EUROSLA Yearbook, 6, 7-25.

https://doi.org/10.1075/eurosla.6.04haw

Hinenoya, K. (2008). Conceptual Complexity and Accessibility of the Article the: Is the Traditional Interpretation of the Enough for ESL Learners?

Ionin, T., Baek, S., Kim, E., Ko, H., \& Wexler, K. (2011). That 's the meaning: Interpretation of definite and demonstrative descriptions in L2-English. Selected Proceedings of the 4th Conference on Generative Approaches to Language Acquisition North America (GALANA 2010), (Galana 2010), 122-138.

Ionin, T., Baek, S., Kim, E., Ko, H., \& Wexler, K. (2012). That 's not so different from the: Definite and demonstrative descriptions in second language acquisition. Second Language Research, 28(1), 69-101. https://doi.org/10.1177/0267658311432200

Ionin, T., Ko, H., \& Wexler, K. (2003). Specificity as a grammatical notion: Evidence from L2-English article use. Proceedings of WCCFL, 245-258.

Ionin, T., Ko, H., \& Wexler, K. (2004). Article Semantics in L2 Acquisition: The Role of Specificity. Language Acquisition, 12(1), 3-69. https://doi.org/10.1207/s15327817la1201

Ionin, T., \& Montrul, S. (2010a). The role of L1 transfer in the interpretation of articles with definite plurals in L2 English. Language Learning, 60(4), 877-925.

https://doi.org/10.1111/j.1467-9922.2010.00577.x

Ionin, T., \& Montrul, S. (2010b). The role of L1 transfer in the interpretation of articles with definite plurals in L2 English. Language Learning, 60(4), 877-925.

https://doi.org/10.1111/j.1467-9922.2010.00577.x

Ionin, T., Zubizarreta, M. L., \& Maldonado, S. B. (2008). Sources of linguistic knowledge in the second language acquisition of English articles. Lingua, 118, 554-576.

https://doi.org/10.1016/j.lingua.2006.11.012

Khazriyati Salehuddin, Tan, K. H., Marlyna Maros, \& Maros, M. (2006). Definiteness And Indefiniteness: A Contrastive Analysis Of The Use Of Determiners Between The Malay Language And English. GEMA Online Journal of Language Studies, 6(1), 21-30.

Kim, K., \& Lakshmanan, U. (2008). L2 article semantics and second language processing. ... Generative Approaches to Second Language, (Gasla 2007), 103-117. Retrieved from http://www.lingref.com/cpp/gasla/9/paper1630.pdf

Kim, K., \& Lakshmanan, U. (2009). The processing role of the Article Choice Parameter: Evidence from L2 learners of English. In Second Language Acquisition of Articles: Empirical findings and theoretical implications (pp. 87-113). https://doi.org/10.1075/lald.49.08kim 


\section{MInstitute Macrothink $^{\text {Int }}$}

Journal of Studies in Education

ISSN 2162-6952 2020, Vol. 10, No. 3

Ko, H., Ionin, T., \& Wexler, K. (2006). Adult L2-learners Lack the Maximality Presupposition, Too! Proceedings of the Inaugural Conference on Generative Approaches to Language Acquisition, 4, 171-182.

Ko, H., Ionin, T., \& Wexler, K. (2009). L2-Acquisition of English Articles by Korean Speakers. The Handbook of East Asian Psycholinguistics: Korean, 286-304. https://doi.org/10.1017/CBO9780511596865.023

Kupisch, T. (2012). Specific and generic subjects in the Italian of German-Italian simultaneous bilinguals and L2 learners. Bilingualism: Language and Cognition, 15(4), 736-756. https://doi.org/10.1017/S1366728911000691

Lee Amuzie, G., \& Spinner, P. (2013). Korean EFL learners' indefinite article use with four types of abstract nouns. Applied Linguistics, 34(4), 415-434.

https://doi.org/10.1093/applin/ams065

Lee, Eun-hee. (2007). English Article Usage in Online Graduate Forums by Non-native EFL Teachers. Indiana University.

Lee, Eunhye. (2012). Transfer at the lexical level in Korean learners' L2 indefinite article use in English. Michigan State University.

Liu, D., \& Gleason, J. L. (2002). Acquisition of the Article the Nonnative Speakers of English An Analysis of Four Nongeneric Uses. Studies in Second Language Acquisition, 24, 1-26. https://doi.org/10.1017/S0272263102001018

Lyons, C. (1999). Definiteness. Cambridge University Press, 380.

https://doi.org/10.1017/CBO9780511605789

Master, P. (1997). The English article system: Acquisition, function, and pedagogy. System, 25(2). https://doi.org/10.1016/S0346-251X(97)00010-9

Master, P. A. (1987). A cross-linguistic interlanguage analysis of the acquisition of the English article system.

Miller, J. (2005). Most of ESL Students Have Trouble with the Articles. International Education Journal, 5(5), 80-88.

Modyanova, N., \& Wexler, K. (2007). Semantic and pragmatic language development: Children know 'that' better. Proceedings of the 2nd Conference on Generative Approaches to Language Acquisition North America, (October 2005), 297-308.

Montrul, S. (2011). Morphological Errors in Spanish Second Language Learners and Heritage Speakers. Studies in Second Language Acquisition, 163-192. https://doi.org/10.1017/S0272263110000720

Montrul, S., \& Ionin, T. (2010). Transfer effects in the interpretation of definite articles by Spanish heritage speakers. Bilingualism, 13(4), 449-473. https://doi.org/10.1017/S1366728910000040 
Morales-Reyes, A., \& Soler, I. G. (2016). Transfer and semantic universals in the L2 acquisition of the English article system by child L2 learners. Language Acquisition, 23(1), 57-74. https://doi.org/10.1080/10489223.2015.1067318

Nik Safiah Karim, Farid M. Onn, Hashim Hj. Musa, \& Abdul Hamid Mahmood. (2006). Tatabahasa Dewan. Dewan Bahasa dan Pustaka (Cetakan Ke). Kuala Lumpur: Dewan Bahasa dan Pustaka.

Nor Hashimah Jalaluddin, Norsimah Mat Awal, \& Kesumawati Abu Bakar. (2008). The Mastery of English Language among Lower Secondary School Students in Malaysia: A Linguistic Analysis. European Journal of Social Sciences, 7(2), 106-119.

Roberts, C. (2002). Demonstratives as definites. In K. van D. and R. K. (eds.) (Ed.), Information Sharing: Reference and Presupposition in Language Generation and Interpretation (pp. 89-196).

Robertson, D. (2000). Variability in the use of the English article system by Chinese learners of English. Second Language Research, 16(2), 135-172. https://doi.org/10.1191/026765800672262975

Snape, N. (2006). The acquisition of the English determiner phrase by Japanese and Spanish learners of English. University of Essex.

Snape, N. (2008). Resetting the Nominal Mapping Parameter in L2 English: Definite article use and the count-mass distinction. Bilingualism Language and Cognition, 11(1), 63-79. https://doi.org/10.1017/S1366728907003215

Snape, N., García Mayo, M. del P., \& Gürel, A. (2013). L1 transfer in article selection for generic referenceby Spanish, Turkish and Japanese L2 learners. International Journal of English Studies, 13(207), 1-28. https://doi.org/10.6018/ijes/2013/1/138701

Snape, N., Leung, Y. I. Y. -k. I., \& Ting, H.-C. (2006). Comparing Chinese, Japanese and Spanish Speakers in L2 English Article Acquisition: Evidence against the Fluctuation Hypothesis? Proceedings of the 8th Generative Approaches to Second Language Acquisition Conference (GASLA 2006), (Gasla), 132-139.

Snape, N., \& Yusa, N. (2013). Explicit Article Instruction in Definiteness, Specificity, Genericity and Perception. In M. Whong, K.-H. Gil, \& H. Marsden (Eds.), Universal Grammar and the second language classroom (Vol. 161, p. 183). Dordrecht: Springer. https://doi.org/10.1007/978-94-007-6362-3

Thomas, M. (1989). The acquisition of English articles by first- and second-language learners. Applied Psycholinguistics, 10(03), 335-355. https://doi.org/10.1017/S0142716400008663

Trenkic, D. (2008). The representation of English articles in second language grammars: Determiners or adjectives? Bilingualism: Language and Cognition, 11(01), 1-18. https://doi.org/10.1017/S1366728907003185 
White, B. (2009). Accounting for L2-English learners' article choices. MSU Working Papers in Second Language Studies, 1(1), 14-37. Retrieved from http://sls.msu.edu/soslap/journal/index.php/sls/article/viewArticle/3

White, L. (2008). Different? Yes . Fundamentally? No . Definiteness Effects in the L2 English of Mandarin Speakers. In Generative Approaches to Second Language Acquisition Conference (pp. 251-261).

Wolter, K. L. (2003). Demonstratives, definite descriptions, and definiteness., University of California at Santa Cruz, (2), 1-42.

Wolter, K. L. (2006). That's that: The semantics and pragmatics of demonstrative noun phrases. University of California.

Wong, B. E., \& Chan, S. H. (2008). The acquisition of English articles by non-native speakers. Jurnal Bahasa Jendela Alam, 5, 700-714.

Wong, B. E., \& Quek, S. T. (2007). Acquisition of the English definite article by Chinese and Malay ESL learners. Electronic Journal of Foreign Language Teaching, 4(2), 210-234.

Xu, Q., Shi, Y., \& Snape, N. (2016). A Study on Chinese Students' Acquisition of English Articles and Interlanguage Syntactic Impairment. Chinese Journal of Applied Linguistics, 39(23859), 459-480. https://doi.org/10.1515/cjal-2016-0029

Zdorenko, T., \& Paradis, J. (2008). The acquisition of articles in child second language English: fluctuation, transfer or both? Second Language Research, 24(2), 227-250. https://doi.org/10.1177/0267658307086302

\section{Appendix 1. Forced-choice written elicited production task (Ionin et al., 2012)}

There are altogether 32 questions. Half of the items (sixteen items) comprised of the definite/demonstrative descriptions while the other half of the items targeted indefinite descriptions. In the test instruments, all the items were blocked and randomised. Only singular NPs were included in the test.

1. Bill is really sick. He has been coughing and sneezing for a long time. He insists that he'll get better soon, as long as he gets enough rest. But he's been sick for two weeks and he isn't getting any better. So his sister tells him, "Go see doctor!”

For each of the four options, please indicate whether it is appropriate in the blank above:

\begin{tabular}{|l|l|l|}
\hline & \multicolumn{1}{|c|}{ Yes } & \multicolumn{1}{c|}{ No } \\
\hline the & & \\
\hline that & & \\
\hline a & & \\
\hline one & & \\
\hline
\end{tabular}




\section{Macrothink}

Which word is the best option for the blank?
$\circ$ the
o that
○ a
o one

a. 'Unique and salient' category: both 'the' and 'that' possible, but 'the' preferred

Rob was really hungry when he came home. He looked in his fridge, and the only thing he found in there was a rather old sandwich. Still, Rob was really hungry, so he ate sandwich. It didn't taste too good.

b. 'Unique and non-salient' category: 'the' preferred over 'that'

Julian loves sweets. He went to a bakery this morning, and bought a cake and a box of cookies. Then he went home and made some tea. Julian sat down with his tea, and ate

cake. He finished it all, to the last crumb!

c. 'Non-unique' category: 'that' preferred over 'the'

Nora bought two sandwiches for lunch. Nora is a vegetarian. One of the sandwiches turned out to have meat in it, so Nora didn't want to eat it. The other sandwich had just vegetables in it. So Nora finished sandwich. But she was still a bit hungry afterwards.

\section{Appendix 2. Picture-based comprehension task (Ionin et al., 2012)}

The task had 40 items, divided into 10 conditions of four items each. The focus of this part of the study was only three singular conditions, exemplified in (b-d). An illustration of how the task given is supposedly carried out is shown in (a).

(a) Here are six houses and six cars.

1. Please draw a star on one house.

2. Now, please draw an arrow above one car.

3. Now, please draw squares around two houses.
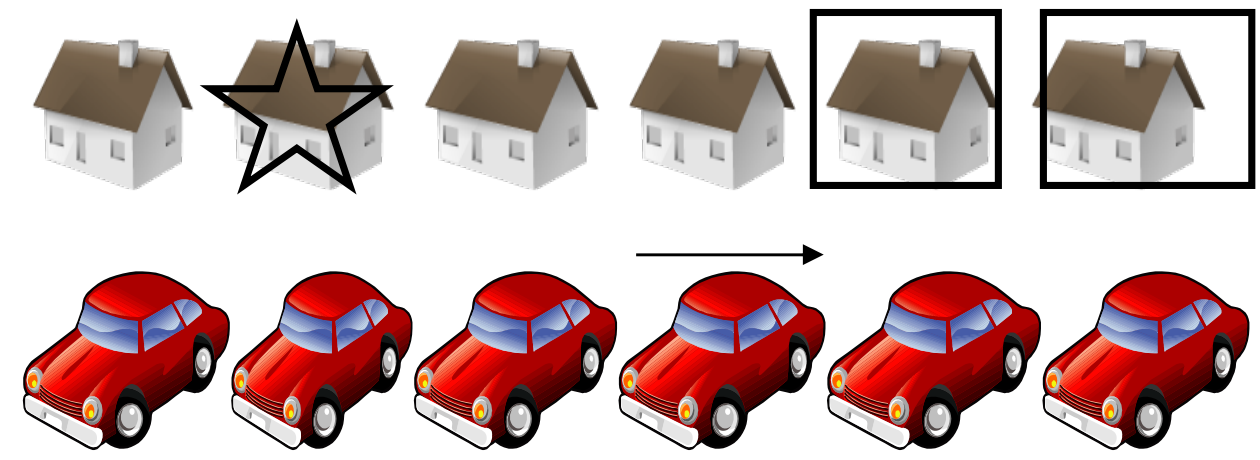

(b) Definite singular condition:

Here are six cups and six houses.

1. Please draw a circle around one cup.

2. Now, please draw an arrow above the cup.

3. Now, please draw a square around one house. 


\section{Macrothink}
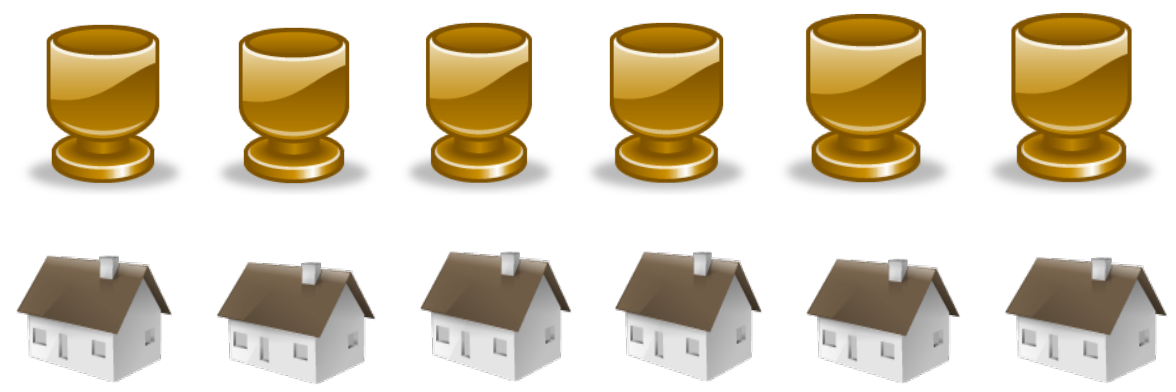

(c) Demonstrative singular condition:

Here are six chairs and six pencils.

1. Please draw a line above one pencil.

2. Now, please draw a star on that pencil.

3. Now, please draw a triangle around one chair.
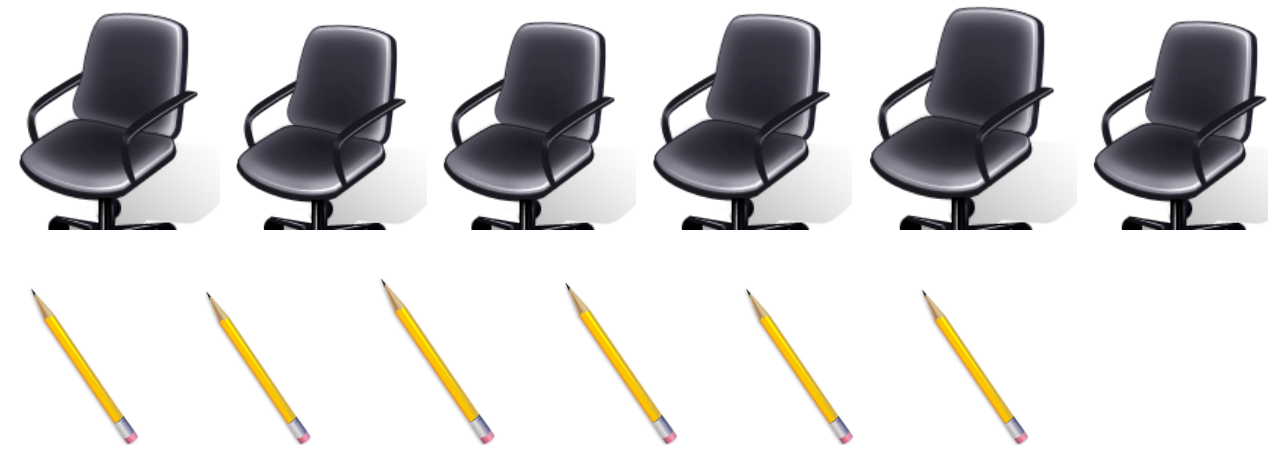

(d) Indefinite singular condition:

Here are six apples and six knives.

Please draw a square around one knife.

Now, please draw a line above a knife.

Now, please draw arrows below three apples.
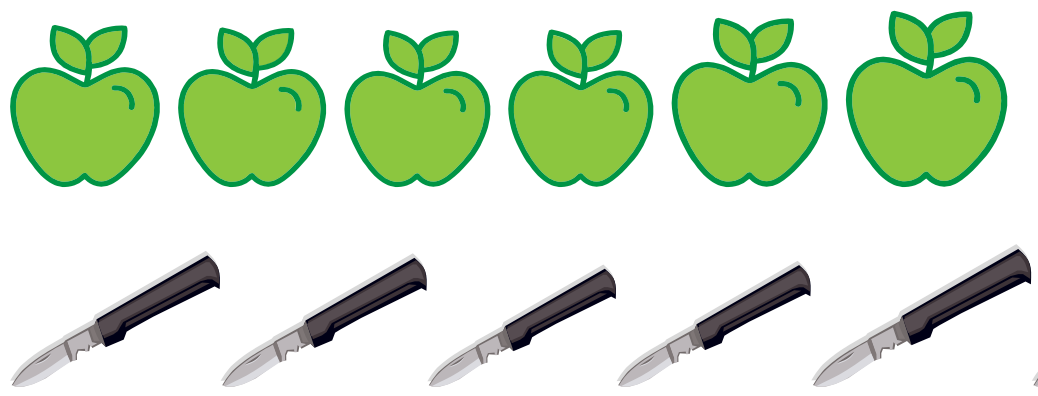

\section{Copyright Disclaimer}

Copyright for this article is retained by the author(s), with first publication rights granted to the journal.

This is an open-access article distributed under the terms and conditions of the Creative 
Commons Attribution license (http://creativecommons.org/licenses/by/3.0/). 